aquecimento médio da atmosfera, na composição da atmosfera e nas inúmeras outras formas em que este efeito vai se manifestar.

ANAL ISE DAS RELAÇOES ENTRE ALGUNS FENOMENOS NATURAIS

Pedro A. Morettin 1

C.M.C. Tolo $i^{1}$

N. Gait ${ }^{1}$

Afrânio R. de Mesquita ${ }^{2}$

1 - Recentemente vários trabalhos trataram do problema de prever os periodos de seca do Nordeste brasileiro através da análise da série de precipitação atmosférica de Fortaleza.

$\mathrm{Na}$ procura das causas da "seca" na área, as relações entre precipitação atmosférica com manchas solares e nivel médio do mar são investigados.

Análise de causalidade, modelos de função de transferência e modelos multivariados ARMA foram aplicados às séries de precipitação de Fortaleza, nivel médio da cidade de São Francisco, USA e à série de manchas solares, números de Wolf.

Os resultados indicam a existência de relações entre nivel médio do mar e precipitação, e uma relação fraca entre manchas solares e precipitação.

2 - Alguns resultados das relações entre as séries. 0 objetivo

1 IME /USP

2 I OUSP 
aqui é avaliar possiveis relações de causalidade entre as séries temporais de precipitação atmosférica de Fortaleza (abreviadamente FORT), de nivel médio do mar em São Francisco, USA (SEA) e de manchas solares (SUN).

São utilizadas as metodologias de Pierce e Haugh (1977) e de Hsiao (1979). O conceito de causalidade usado é devido a Granger (1969). Os detalhes destas metodologias podem ser vistos em Morettin et al. (1988).

2.1 - Metodologia de Pierce e Haugh. Essa metodologia consiste em modelar as séries em pares, utilizando modelos ARIMA (auto regressivos, integrados, médias móveis) e correlacionar os residuos dos modelos.

Para o par (SEA, FORT), detectou-se uma causalidade de SEA para FORT, SEA $\rightarrow$ FORT, sendo que FORT lidera SEA com uma defasagem de 1 ano. Além disso, foi detectada causalidade instantânea entre as duas séries, mas esta encontra-se sujeita a criticas (Layton, 1984). A causalidade encontrada foi classificada como moderada. Os demais pares (SEA, SUN) e (SUN, FORT) estão sendo investigados.

2.2 - Metodologia de Hsiao. Aqui, o objetivo é estabelecer modelos bivariados da forma

$$
\begin{aligned}
& y_{t}=\psi_{11}(B) x_{1}+\psi_{12}(B) y_{t}+u_{t} \\
& x_{t}=\psi_{21}(B) x_{t}+\psi_{22}(D) y_{t}+v_{t}
\end{aligned}
$$

a fim de detectar padrões de causalidade.

(a) $\operatorname{Par}$ (SEA, FORT)

Aqui, os modelos encontrados indicam que SEA $\rightarrow$ FORT havendo, também, causalidade instantânea. Os modelos são da forma: 


$$
\begin{aligned}
& \text { FORT }_{t}=\alpha_{1} \text { SEA }_{t}+\alpha_{2} \text { SEA }_{t-1}+\ldots+\alpha_{5} \mathrm{SEA}_{t-5}+U_{t} \\
& \text { SEA }_{t}=\beta_{1} \mathrm{SEA}_{t-1}+\ldots+\beta_{6} \mathrm{SEA}_{\mathrm{t}-1}+\mathrm{V}_{\mathrm{t}}
\end{aligned}
$$

Vê-se que FORT 1 idera SEA com defasagens de 1 a 5 anos, diferente ao que ocorre com a análise de Pierce e Haugh.

(b) Para os pares (SEA, SUN) e (SUN, FORT) não foram detectados padrões de causalidade. Causalidade instantânea está sendo verificada em ambos os casos.

Estas análises preliminares indicam que:

(i) Metodologias diferentes podem conduzir a resultados diferentes.

(ii) Embora as análises não estejam concluídas, parece não haver relações entre precipitação e atividade solar, bem como entre atividade solar e nivel médio do mar.

Uma causalidade moderada entre nivel médio do mar e precipitação foi detectada.

( $i$ ii) Análises feitas no domínio da freqüência (Brillinger, 1968) indicaram uma correlação moderada entre atividade solar e precipitação em Santa Fé (USA).

Modelos de função de transferência estão sendo testados para o par (SEA, FORT).

3 - 0 "teste" de comporientes periódicas em séries temporais oceanográficas, Geofísicas, Meteorológicas e Astronômicas é um problema de alta relevância.

Os testes devidos a Fisher, Whittle, Hannan Bartlett, Priestley e Siegel foram desenvolvidos em "software" adequados e aplicados com sucesso em séries de precipitação atmosférica da cidade de Fortaleza, CE, Brasil. Encontra-se por outro lado, em desenvolvimento um teste de alta sensibilidade, baseado na fase das componentes periódicas. 

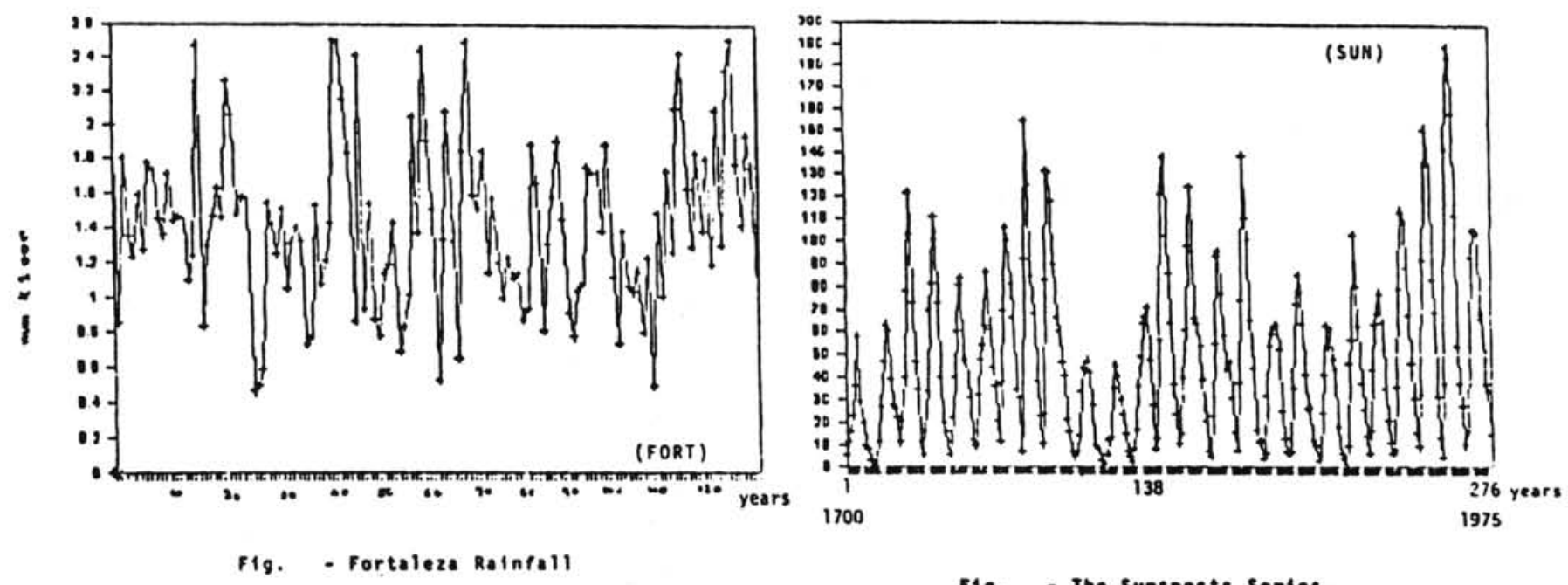

F1g. - The Sunsposts series.
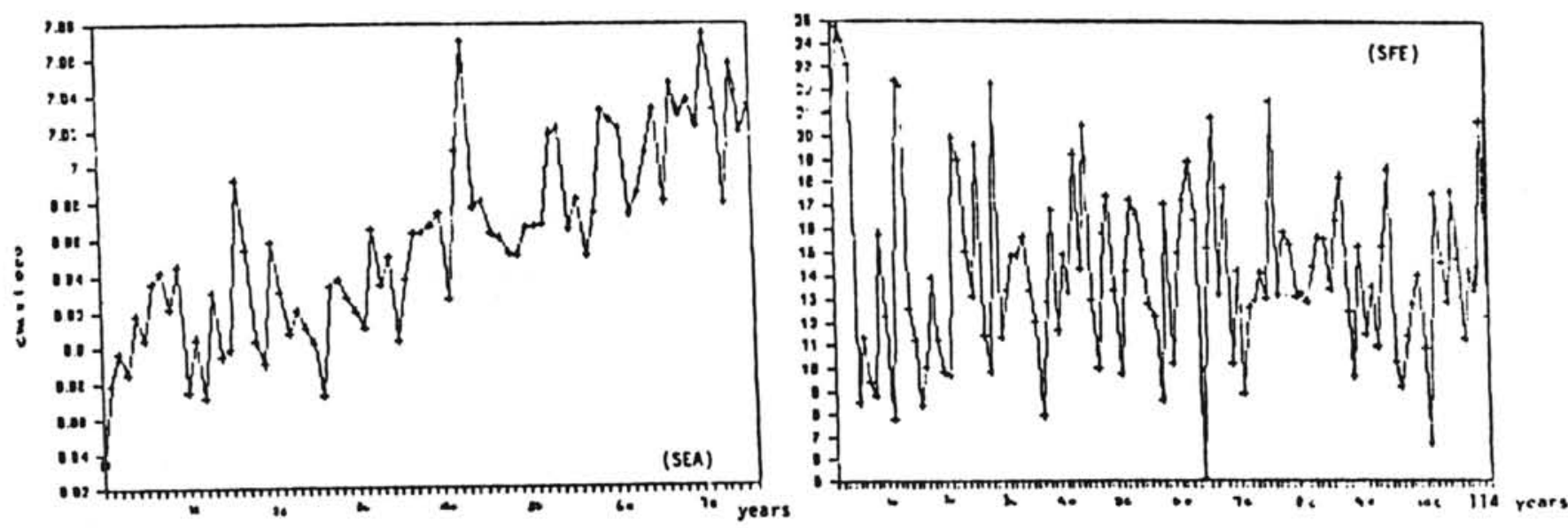

Fig. - Mean sea Level at San Francisco

Fig. Rainfall at santa fë.

Através da aplicação desses testes foi possivel a identificação de duas componentes periódicas na série de Fortaleza, possibilitando a derivação do modelo harmônico de previsão para as componentes de periodos 26 e 13 anos:

$$
\begin{aligned}
X_{t}= & 1424,3+205,56 \cos (0,2398 t+1,99)+ \\
& 255,64 \cos (0,4796 t+2,20)+Y_{t}
\end{aligned}
$$

onde $X_{t}$ é chuva em mm, e $t$. tempo em anos e $Y_{t}$ tem espectro 
continuo.

4 - Os objetivos do grupo de trabalho são: a) Dar continuidade ao desenvolvimento de testes de prioridades e métodos estatisticos para determinar relações de causalidade, a partir de séries de fenômenos naturais na faixa espectral de décadas a séculos; b) Utilizar tais desenvolvimentos em análises de séries globais de precipitação atmosférica, nivel médio do mar, radiação solar e outras, estabelecendo modelos estatisticos entre as diferentes variáveis; e, c) obter tais dados, provenientes de várias localidades do globo, através da cooperação internacional, dentro do "Global Change".

\section{AS MUDANÇAS CLIMATICAS, OS DESLOCAMENTOS DOS ECOSSISTEMAS TERRESTRES E ASPECTOS RELACIONADOS}

Paulo Nogueira-Neto

Os ecossistemas são unidades integradas e funcionais, com uma parte biótica e outra abiótica. A esse conceito clássico, acrescento o do ECOBALANCEAMENTO, como explicarei mais adiante.

Os climas e solos são os principais componentes abióticos dos ecossistemas terrestres. Cumpre resialtar que os ecossistemas terrestres devem ser considerados não apenas como unidades funcionais e integradas, mas também como unidades onde climas, solos (inclusive a capacidade de reter água) e os

1Depto Ecologia Geral IB-USP 